\title{
Assessment of platelet function with light transmission aggregometry in 24 patients supported with a continuous-flow left ventricular assist device: A single-center experience
}

\author{
Mathieu Fiore, MD, ${ }^{\mathrm{a}, \mathrm{b}, \mathrm{c}}$ Chloé James, MD, PhD, ${ }^{\mathrm{a}, \mathrm{b}, \mathrm{c}}$ Christine Mouton, MD, ${ }^{\mathrm{a}}$ Joachim Calderon, MD, ${ }^{\mathrm{b}, \mathrm{c}, \mathrm{d}}$ \\ Laurent Barandon, $\mathrm{MD}, \mathrm{PhD},{ }^{\mathrm{b}, \mathrm{c}, \mathrm{e}}$ Alexandre Ouattara, $\mathrm{MD}, \mathrm{PhD},{ }^{\mathrm{b}, \mathrm{c}, \mathrm{d}}$ and François Picard, $\mathrm{MD}^{\mathrm{f}}$
}

\begin{abstract}
Objectives: This study evaluated platelet function for an extended period of time in patients with a HeartMate II continuous-flow left ventricular assist device (Thoratec Corporation, Pleasanton, Calif) with light transmission aggregometry and investigated the potential role of this test in clinical management.
\end{abstract}

\begin{abstract}
Methods: Twenty-four patients were studied prospectively after implantation. Mean duration of support was 8.5 months. Platelet functions were assessed with light transmission aggregometry induced by thrombin receptor agonist peptide, ristocetin, or arachidonic acid. All patients received an aspirin regimen that was progressively increased until arachidonic acid-triggered platelet aggregation dropped lower than $20 \%$. Plasma levels of von Willebrand factor were also determined when ristocetin-induced platelet agglutination was impaired.
\end{abstract}

Results: Intensity of platelet aggregation with thrombin receptor agonist peptide was little changed in patients with a HeartMate II relative to control subjects. Aspirin dose greater than $160 \mathrm{mg} / \mathrm{d}$ was progressively required in $46 \%$ of patients. Ristocetin-induced platelet agglutination was impaired in 4 patients in association with a lack of high molecular weight von Willebrand factor multimers. Three patients had thromboembolic events $(12.5 \%)$ and $8(33 \%)$ suffered from major bleeding complications.

Conclusions: High platelet reactivity during treatment with aspirin is common in patients with a HeartMate II. Moreover, light transmission aggregometry may detect impaired ristocetin-induced platelet agglutination, enabling dosage of aspirin to be adjusted. Our strategy showed no major improvements in terms of thrombosis rate when compared with published data, although bleeding frequency was somewhat reduced. Benefits of light transmission aggregometry testing need to be assessed in a larger randomized study with a longer follow-up. (J Thorac Cardiovasc Surg 2014;148:3119-25)

See related commentary on pages 3125-6.

Supplemental material is available online.

From the Laboratoire d'Hématologie, ${ }^{\mathrm{a}}$ CHU de Bordeaux, Pessac, France; the Université Bordeaux II, ${ }^{\mathrm{b}}$ Bordeaux, France; the Adaptation Cardiovasculaire à l'Ischémie, ${ }^{c}$ INSERM U1034, Pessac, France; the Service d'Anesthésie-Réanimation II, ${ }^{\mathrm{d}} \mathrm{CHU}$ de Bordeaux, Pessac, France; the Département de Chirurgie Cardiaque, ${ }^{\text {e }}$ Hôpital Cardiologique du Haut-Lévêque, Pessac, France; and the Unité de Traitement de l'Insuffisance Cardiaque, ${ }^{\mathrm{f}}$ Hôpital Cardiologique du Haut-Lévêque, Pessac, France.

Disclosures: Chloé James reports consulting and lecture fees from Shire Biopharmaceuticals. Alexandre Ouattara reports consulting fees from Air Liquid and the Medicines Company, and lecture fees from LFB and ABBVIE. Christine Mouton reports lecture fees from LFB and Bayer Healthcare. François Picard reports lecture fees from Servier, GSK, and Actelion. All other authors have nothing to disclose with regard to commercial support.

Received for publication Jan 28, 2014; revisions received June 9, 2014; accepted for publication July 12, 2014; available ahead of print Sept 8, 2014.

Address for reprints: Mathieu Fiore, MD, Laboratoire d'Hématologie, Hôpital Cardiologique, 33604 Pessac, France (E-mail: mathieu.fiore@ chu-bordeaux.fr). $0022-5223 / \$ 36.00$

Copyright $\odot 2014$ by The American Association for Thoracic Surgery

http://dx.doi.org/10.1016/j.jtcvs.2014.07.091
Left ventricular assist devices (LVADs) are mechanical blood pumps that are increasingly being used to treat severe heart failure (eg, as a bridge to heart transplant, to allow myocardial recovery, or as a long-term therapy). The HeartMate II (Thoratec Corporation, Pleasanton, Calif) is among the most commonly used LVAD systems. ${ }^{1-4}$

Among the associated risks, LVADs are still associated with thromboembolic events, which remain at $5 \%$ to $15 \%$ despite developments in device technology, anticoagulation and antiplatelet strategies. ${ }^{5}$ Indeed, the "foreign" surfaces of LVADs alter rheologic conditions, and blood stasis within the chambers of the native heart can induce activation of coagulation, which requires adequate anticoagulation to prevent thromboembolic events. ${ }^{6}$ Because platelet function is generally assumed to play a key role in these deleterious complications, antiplatelet therapy is considered crucial for such patients; anti-vitamin $\mathrm{K}$ anticoagulation is usually given in association with at least 1 antiplatelet agent. ${ }^{5,7}$

In addition, these patients are exposed to increased bleeding tendencies caused by possible impaired platelet function or acquired von Willebrand disease related to the high shear stress induced by the device. ${ }^{8}$ Only a few studies have examined platelet functions in patients with LVAD support. ${ }^{5}$ Houël 


\section{Abbreviations and Acronyms \\ $\mathrm{AA}=$ arachidonic acid \\ COX $=$ cyclooxygenase \\ INR = international normalized ratio \\ LTA $=$ light transmission aggregometry \\ LVAD $=$ left ventricular assist device \\ TRAP $=$ thrombin receptor activating peptide \\ $\mathrm{vWF}=$ von Willebrand factor}

and colleagues ${ }^{9}$ studied the efficacy of aspirin with light transmission aggregometry (LTA) in 15 patients in whom an external ventricular assist device had been implanted; however, these patients were only studied during a 6-week period after implantation. Our knowledge of platelet function in patients with LVAD remains limited, and the long-term follow-up of such patients has not been well described. Monitoring of platelet function may therefore be necessary to manage an implanted LVAD to reduce thrombotic and bleeding risks.

To that effect, the aim of this study was to test, with LTA, whether the HeartMate II impaired platelet function, and to investigate the possible role of LTA in the clinical management of patients supported with the HeartMate II in the early, intermediate, and late phases after implantation.

\section{MATERIALS AND METHODS \\ Inclusion of Patients}

Patients who underwent implantation of a HeartMate II and who had given their consent were enrolled in this observational study between April 2011 and June 2013. Clinical data were obtained from the patients' medical records. During follow-up visits, patients were systematically assessed for symptoms of bleeding or thromboembolism, and any other concerns or complications related to their devices were noted and investigated.

Control patients were healthy subjects who were not receiving any drugs that might impair platelet function.

This observational study was approved by our institutional review board (Comité de Protection des Personnes Sud-Ouest et Outre Mer III, Bordeaux, France).

\section{Testing Platelet Function With LTA}

Platelet-rich plasma was obtained by centrifugation of $0.129-\mathrm{mol} / \mathrm{L}$ $(3.8 \%)$ citrated blood tubes (BD Vacutainer; Becton, Dickinson and Company, Franklin Lakes, NJ) at 1100 rpm for 10 minutes. LTA was performed without adjusting the platelet count with $0.5-\mathrm{mg} / \mathrm{mL}$ arachidonic acid (AA; $\mathrm{Nu}$ Chek Prep, Elysian, Minn), 1.5-mg/mL ristocetin (Diagnostica Stago, Asnières sur Seine, France) and with $50-\mu \mathrm{mol} / \mathrm{L}$ thrombin receptor activating peptide (TRAP; Neosystem SA, Strasbourg, France) with an APACT 4004 aggregometer (Elitech, Salon de Provence, France). TRAP is a synthetic peptide that mimics the effects of thrombin on platelets; it allows activation of protease-activated receptors, leading to platelet aggregation. It is a strong platelet agonist, and an abnormal response to high concentrations of TRAP may reflect severely impaired platelet function. Moreover, at high concentrations of TRAP, protease-activated receptor pathways are not affected by aspirin intake, thus reflecting approximate platelet baseline reactivity. Maximal intensity was recorded for 10 minutes and expressed as percentage change in transmittance.

\section{Antiplatelet Therapy and Anticoagulation Protocol for HeartMate II}

Anti-vitamin K therapy (fluindione) was started when postoperative bleeding was acceptable, typically on day 2 after surgery, to maintain the international normalized ratio (INR) between 2 and 3 .

Parenteral aspirin therapy was switched to oral therapy when oral feeding became possible. Aspirin therapy, at a daily dose of 75 to $100 \mathrm{mg}$, was administered for 24 to 48 hours after device placement, when basal platelet function was considered almost normal and there was an absence of related bleeding. When possible, patients were tested weekly while in the hospital (early phase, $<1$ month, and intermediate phase, 1-3 months). After discharge, patients attended monthly follow-up visits at the study center's clinic (late phase, $>3$ months).

The aspirin regimen was progressively increased $(160 \mathrm{mg} / \mathrm{d}$ to $300 \mathrm{mg} / \mathrm{d}$ to $500 \mathrm{mg} / \mathrm{d}$ ) until AA-triggered platelet aggregation dropped below $20 \%$. Biologic aspirin resistance was defined by any persistent ex vivo platelet aggregation greater than $20 \%$ induced by AA, independent of the daily dose of aspirin used. ${ }^{10}$

\section{von Willebrand Factor Studies}

When ristocetin-induced platelet agglutination was impaired, complementary von Willebrand factor (vWF) studies were performed. The PFA-100 point-of-care assay (Siemens, Marburg, Germany) assessed platelet function in whole blood under conditions of high shear stress. Standard collagen/epinephrine or collagen/adenosine diphosphate cartridges were used. Aspirin treatment usually prolongs collagen/epinephrine closure time but not collagen/adenosine diphosphate closure time. The plasma antigen vWF was measured with the LIATEST vWF:Ag kit (Diagnostica Stago), and vWF ristocetin-cofactor activity was measured with reagents from Helena Biosciences Europe (Helena Biosciences Europe, Gateshead, UK). Multimeric patterns of vWF were determined by lowresolution gel electrophoresis (1.2\% sodium dodecylsulfate agarose) in a Multiphor II Electrophoresis system (GE Healthcare Life Sciences, Piscataway, NJ) and visualized with peroxidase-conjugated anti-vWF IgG antibodies (DAKO, Glostrup, Denmark). High-molecular-weight multimer profiles were compared with those of normal human plasma.

\section{Statistical Analyses}

Data are expressed as mean \pm SD for normally distributed continuous variables, as median with interquartile range for nonnormally distributed continuous variables, and as number and percentage of patients for categoric data. The normal distribution of continuous variables was assessed with skewness and kurtosis statistical tests. A Mann-Whitney $\mathrm{U}$ test was conducted to compare median values. Statistical analyses were performed with the SPSS statistical software package (IBM, Armonk NY).

\section{RESULTS \\ Patients Characteristics}

We prospectively enrolled 24 patients during the study period. Only 3 patients were female. The overall median age was $57 \pm 12$ years. Eleven of the patients underwent LVAD placement under emergency conditions. All characteristics of the patients are summarized in Table 1.

\section{Impact of HeartMate II Treatment on Platelet Function}

Our aim was to investigate whether implantation of a HeartMate II was associated with severely impaired platelet function. In the early, intermediate, or late phase after LVAD implantation, values of TRAP-induced platelet aggregation showed that basal platelet function was only slightly diminished relative to normal control values 
TABLE 1. Characteristics of included patients $(n=24)$

\begin{tabular}{lc}
\hline Sex (male/female ratio) & $21: 3$ \\
Age (y) & $57 \pm 12$ \\
Underlying heart disease & \\
$\quad$ Ischemic heart failure & 21 \\
$\quad$ Dilated cardiomyopathy & 3 \\
LVAD placement & \\
$\quad$ Under emergency conditions & 11 \\
$\quad$ Scheduled for surgery & 13 \\
ICU stay (d) & $12(7-16)$ \\
Hospital stay (d) & $59(41-68)$ \\
Duration of follow-up (mo) & $7(2-13)$ \\
\hline Data are expressed as number and percentage of patients $(\%)$ mean \pm SD, or median
\end{tabular}

ware expressed as number and percentage of with interquartile range. $L V A D$, Left ventricular assist device; $I C U$, intensive care unit.

(mean $\Delta$ TRAP values of $11 \%$ and $7 \%$, respectively, at 1 and 6 months), suggesting an absence of severely impaired platelets in our patients (Figure 1).

Patients were also closely monitored with LTA to optimize the dosage of aspirin. With a cutoff value of a $20 \%$ LTA response to AA, an aspirin dose greater than $75 \mathrm{mg} / \mathrm{d}$ was progressively required by $92 \%$ ( 22 of 24 ) of patients, and a dose greater than $160 \mathrm{mg} / \mathrm{d}$ was required by $46 \%$ ( 11 of 24 ) (Table 2 ). In some patients, aspirin resistance was observed at several months after HeartMate II implantation, suggesting that this condition may persist throughout LVAD support (Figure E1).

Ristocetin-induced platelet agglutination was impaired in 4 of the 24 patients (Figure 2, $A$ ). Collagen/epinephrine closure time and collagen/adenosine diphosphate closure time were significantly prolonged in 3 patients (Table 3 ). Average plasma concentrations of $\mathrm{vWF}$ protein, $\mathrm{vWF}$ cofactor activity and factor VIII:C were elevated in all 4 patients, which suggests an inflammatory condition induced by the device (Table 3). A vWF multimeric analysis was therefore performed, even though laboratory vWF values were normal; this showed a lack of high-molecular-weight multimers and confirmed an acquired von Willebrand disorder in these patients (Figure 2, $B$ ).

\section{Adverse Events Associated With Defects in Platelet Function}

The mean INR for all patients during support was $2.03 \pm$ 0.45 . Because the aspirin dose regimen was progressively

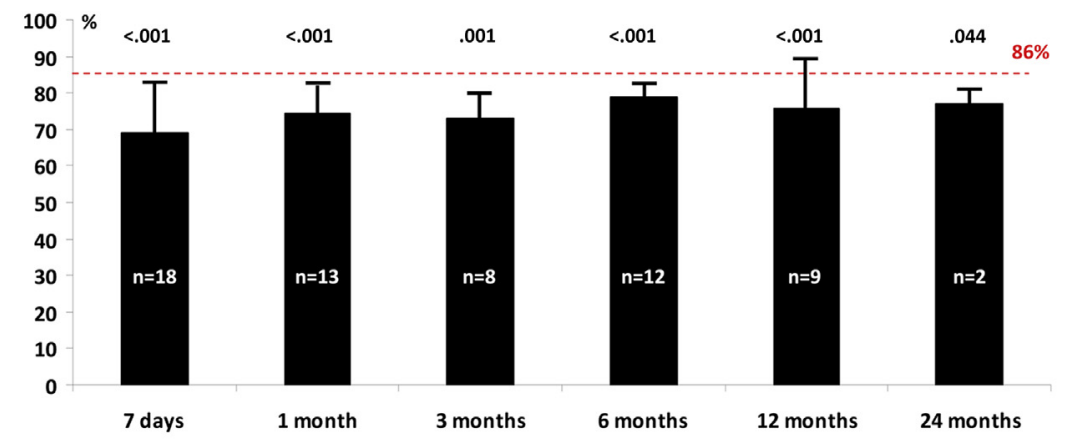

A

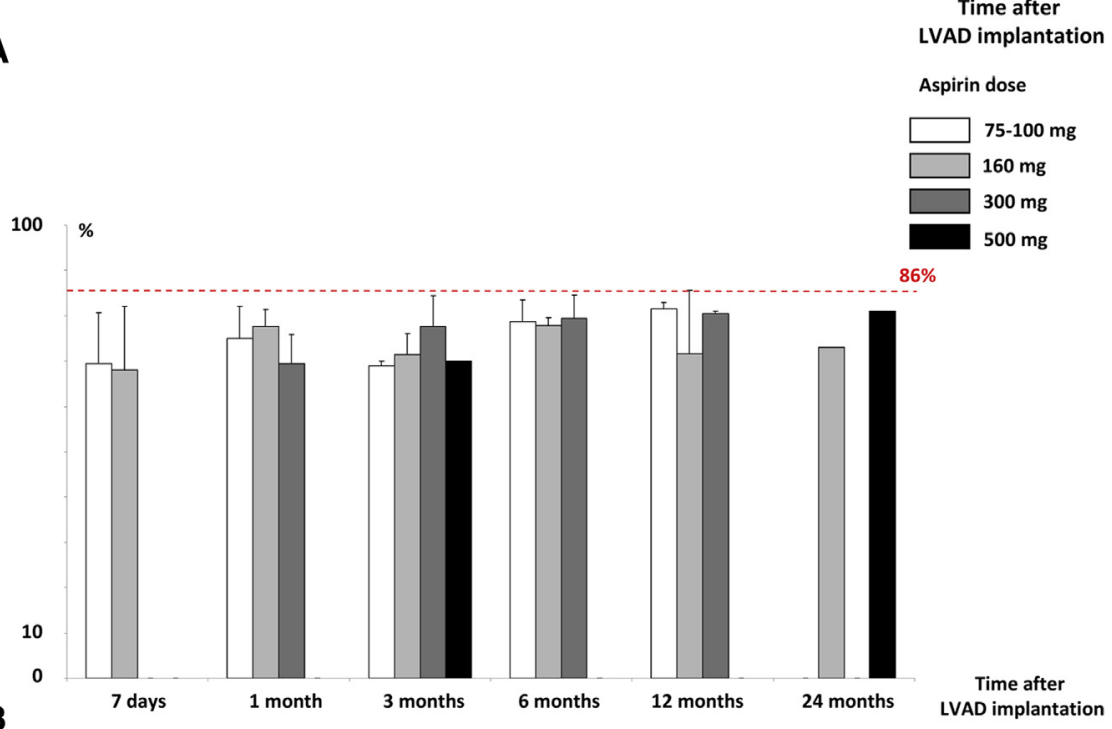

FIGURE 1. A, Platelet aggregation induced by thrombin receptor activating peptide $(50 \mu \mathrm{mol} / \mathrm{L})$ during left ventricular assist device ( $L V A D)$ support. Numbers above bars represent $P$ values. B, Function additionally broken down by aspirin dosing. The dashed red line corresponds to the average percentage of maximal platelet aggregation in 30 healthy subjects. 
TABLE 2. Effect of aspirin on platelet inhibition in the 24 patients with a HeartMate II

\begin{tabular}{lcc}
\hline Response to aspirin & AS & AR \\
\hline Total patients & $20(83 \%)$ & $4(17 \%)$ \\
Aspirin dose $(\mathrm{mg} / \mathrm{d})$ & & \\
$75-100$ & $2(8.3 \%)$ & $2(8.3 \%)$ \\
160 & $9(37.5 \%)$ & $1(4.2 \%)$ \\
300 & $8(33.3 \%)$ & $1(4.2 \%)$ \\
500 & $1(4.2 \%)$ & $0(0 \%)$ \\
\hline
\end{tabular}

Data are expressed as numbers and percentages of patients. AS, Aspirin sensitivity; $A R$, aspirin resistance.

increased, we were specifically interested in the occurrence of major bleeding events that occurred a long time after surgery. According to this study, 8 patients $(33 \%)$ had a major bleeding complication; these were an intracerebral hemorrhage, psoas muscle hematoma, and gastrointestinal bleeding from colonic lesion or cecal angiodysplasia. Among these patients, only 3 required an aspirin dose of $300 \mathrm{mg} / \mathrm{d}$, whereas the others received 75 to $160 \mathrm{mg} / \mathrm{d}$. Two of the patients who received $300 \mathrm{mg} / \mathrm{d}$ also had impaired ristocetin-induced platelet agglutination and a lack of high-molecular-weight vWF multimers, which probably increased their risk of bleeding. Finally, INR remained within normal limits in 6 of the 8 patients with bleeding events.

Only 3 patients $(12.5 \%)$ had thromboembolic events, corresponding to pump thrombosis or ischemic stroke. Notably, these complications were not associated with biologic aspirin resistance or hypoanticoagulation. Indeed, in all cases, INRs at the time of the clotting even were within expected values (between 2 and 3 ).

\section{DISCUSSION}

In recent years, the use of mechanical circulatory support as a bridge to transplant has become a reliable and safe treatment modality because of the significant gain in clinical experience. ${ }^{11}$ However, despite meticulous efforts to manage anticoagulation and antiplatelet therapy, thromboembolic events still may occur, and reduced platelet function can be an important risk factor for increased bleeding. ${ }^{12}$ Our study focused on platelet function in patients with a HeartMate II implant. Our major findings are that (1) most of the patients with HeartMate II implants required high doses of aspirin to reduce maximum AA-induced platelet aggregation and (2) a data-based approach to modulating aspirin dose did reduce the bleeding relative to rates usually reported at comparable dose levels of aspirin.

Indeed, we used LTA to optimize the dose of aspirin in patients with HeartMate II implants and showed that a small proportion of them were sensitive to a dose of $75 \mathrm{mg} / \mathrm{d}$, which reduced the maximum AA-induced platelet aggregation to less than $20 \%$. In outpatients with stable coronary artery disease, aspirin efficacy has been observed at low doses, but with some individual variability. ${ }^{13}$ With a cutoff of value of a $20 \%$ LTA response to AA, Blann and associates ${ }^{14}$ showed that more than $67 \%$ of 175 patients with stable coronary artery disease were aspirin sensitive at a dose of $75 \mathrm{mg} / \mathrm{d} .{ }^{14}$ We found that biologic aspirin hyporesponsiveness is common in patients after Heart Mate II implantation, even in the intermediate and late phases. This finding is in agreement with a previous report, which showed a resistance to aspirin in $26 \%$ of the patients despite $250-\mathrm{mg} / \mathrm{d}$ aspirin treatment. However, those patients were only studied during a 6-week period after implantation, whereas the mean follow-up period of our study was 8.5 months. ${ }^{9}$

A prolonged inflammatory reaction is observed in patients who have an implanted $\operatorname{LVAD}^{15,16}$; enhanced regeneration of new platelets in response to stress and

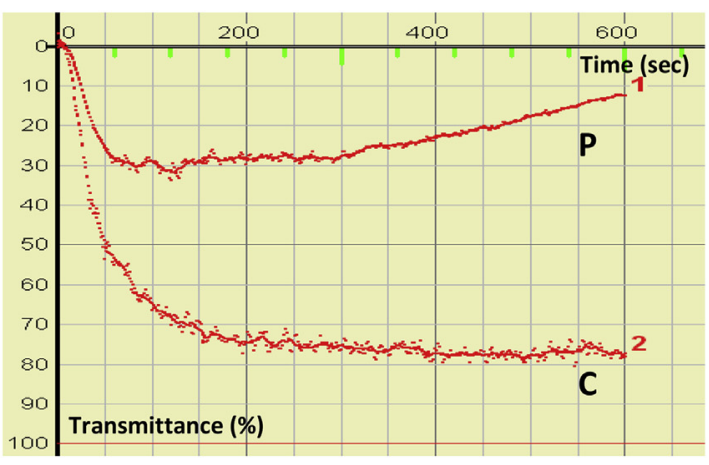

A

FIGURE 2. A, Platelet agglutination induced by ristocetin $(1.5 \mathrm{mg} / \mathrm{mL})$, showing a diminished response in a patient $(P)$ with HeartMate II support relative to the control value $(C)$. B, Western blot analysis of von Willebrand factor showing a loss of high-molecular-weight multimers in a patient $(P)$ relative to a control subject $(C)$. 
TABLE 3. Laboratory values for von Willebrand factors, platelet counts, and closure times of the 4 patients with a HeartMate II and impaired ristocetin-induced platelet agglutination

\begin{tabular}{|c|c|c|c|c|c|c|c|}
\hline Patient & $\begin{array}{c}\text { vWF:Ag } \\
(\%, \text { 50-150) }\end{array}$ & $\begin{array}{c}\text { vWF:RCo } \\
(\%, \mathbf{5 0 - 1 5 0 )} \\
\end{array}$ & FVIII $(\%, 50-150)$ & $\mathrm{RCo} / \mathrm{RAg}$ ratio & Platelets $\left(10^{9}\right.$ cells/L) & CEPI-CT (s) & CADP-CT (s) \\
\hline 1 & 138 & 113 & 97 & 1.2 & 133 & - & - \\
\hline 2 & 212 & 130 & 284 & 0.6 & 541 & $>300$ & 297 \\
\hline 3 & 296 & $>240$ & 233 & $>0.8$ & 170 & $>277$ & 200 \\
\hline 4 & 283 & 178 & 230 & 0.8 & 222 & $>300$ & $>300$ \\
\hline
\end{tabular}

inflammation could explain the resistance to aspirin in these patients. ${ }^{17-19}$ Indeed, the entry of new platelets containing active cyclooxygenase (COX) into circulation may counteract the complete and persistent suppression of thromboxane biosynthesis by aspirin. ${ }^{20}$ It is also known that platelet thromboxane formation principally depends on COX-1, the constitutive isoform of COX. ${ }^{21}$ Nevertheless, careful analysis of COX isoforms in platelets have also revealed a small amount of the inducible isoform COX-2, which is 170 -fold less sensitive to inhibition by aspirin. $^{22,23}$ A study has demonstrated that an increased platelet turnover elevated platelet COX-2, and it has been speculated that platelet resistance to aspirin may be induced by COX-2 generating critical amounts of thromboxane. ${ }^{24}$ All these observations may suggest that aspirin resistance in patients with LVADs can be overcome by the administration of higher doses, as we observed in our study. In 4 cases, however, impaired platelet inhibition was averted by administering aspirin twice daily, thereby reversing a shorter lasting effect of aspirin related to the faster renewal of platelets. One of our patients had aspirin dose adjusted to
$75 \mathrm{mg}$ twice daily, rather than $160 \mathrm{mg}$ once daily, and 3 others had the dose adjusted to $160 \mathrm{mg}$ twice daily rather than $300 \mathrm{mg}$ once daily. The reduction of thromboxane $\mathrm{B}_{2}$ levels related to an increased aspirin dose could support this hypothesis. Nonetheless, whether these patients are less sensitive to the effects of aspirin still remains to be defined and needs to be further explored. Other studies in larger patient populations are necessary to identify new and specific markers of aspirin resistance in such patients.

We also examined whether ristocetin-induced platelet agglutination defects were caused by vWF abnormalities. HeartMate II appears to induce an acquired vWF disease similar to that previously observed in patients with aortic stenosis or other cardiac defects. ${ }^{25-29}$ Uriel and colleagues $^{26}$ measured high-molecular-weight vWF multimers in 31 patients with HeartMate II support and showed that these multimers were reduced in all patients, yet only 18 of the $31(58 \%)$ patients had a bleeding episode. In our study, only 4 patients $(17 \%)$ had impaired ristocetin-induced platelet agglutination associated with a lack of high-molecular-weight vWF multimers. This result

HMII implantation

Normal basal platelet functions and absence of bleeding

24-48 h

Aspirin therapy at a daily dose of $75-100 \mathrm{mg}$

LTA at weekly intervals during hospitalization

Aspirin dose management to optimal biological effect

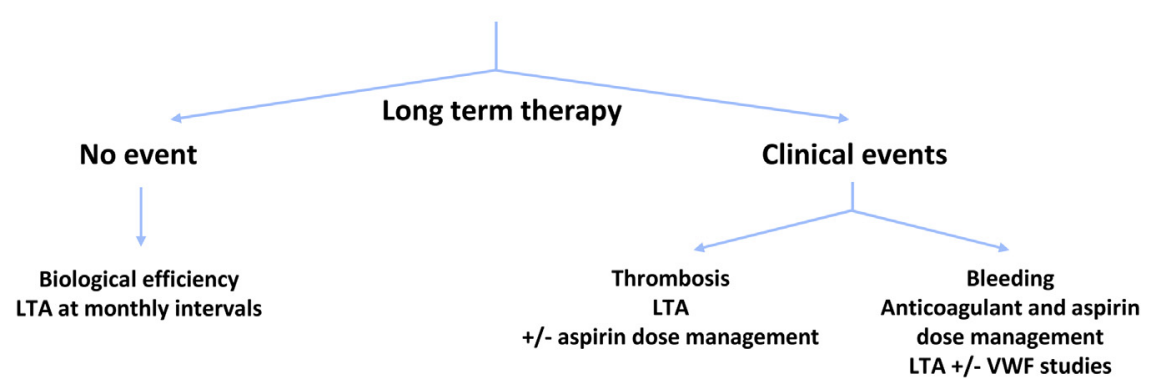

FIGURE 3. Clinical algorithm and proposals to use light transmission aggregometry (LTA), to manage the treatment of patients with a HeartMate II $(H M I I) . V W F$, von Willebrand factor. 
suggests that LTA is not sensitive enough to detect abnormalities of vWF in patients with LVAD support. Nonetheless, in 3 of these 4 cases, impaired ristocetininduced platelet agglutination was associated with a major bleeding event. The etiology of bleeding events in patients treated with the HeartMate II is multifactorial, and the LTA test may suggest a specific cause. Finally, LTA enabled us to adapt and reduce aspirin dose for these patients.

Previous studies have shown that thromboembolic events in patients with LVAD support occur in $5 \%$ to $15 \%$ of cases, whereas bleeding events are reported in $30 \%$ to $50 \%$ of cases. ${ }^{5,30}$ In contrast to the approaches used in previous studies, we made adjustments to aspirin dosage for a long period after HeartMate II implantation to improve long-term outcomes. In our study, 3 patients $(12.5 \%)$ had some thromboembolic event, and $8(33 \%)$ had a major bleeding complication. Thus, in this particular population, LTA monitoring with adjustment of aspirin therapy did not significantly improve the rate of thromboses relative to other published data; however, bleeding frequency was somewhat reduced. LTA testing with adjustment of aspirin dose had no impact on other prognostic factors, such as adherence to treatment, procedure-related technical factors, or other coexisting conditions. We cannot, however, exclude the possibility of greater benefits of LTA testing in a larger randomized study with a prolonged follow-up. Moreover, our patient recruitment varied somewhat from previously published data on patients with HeartMate II support, which reported that $20 \%$ of patients were female, and sex bias may be associated with potential significant confounding variables.

Finally, on the basis of our results, we can propose a clinical algorithm that uses LTA, to manage patients with a HeartMate II (Figure 3). Low-dose aspirin therapy may be administered for 24 to 48 hours after device placement, when basal platelet functions are considered almost normal. The aspirin regimen is then progressively increased until AA-triggered platelet aggregation drops below $20 \%$. If LTA detects impaired ristocetin-induced platelet agglutinations, then vWF studies are performed to evaluate vWF level, function, and multimeric distribution. Anticoagulant or platelet antiaggregating agents are then adjusted according to the clinical situation and laboratory test results.

In conclusion, we have successfully used LTA to test platelet function and to optimize the dose of aspirin for 24 patients supported with the HeartMate II. Further studies are required, however, to establish the role of LTA as a guide to monitor aspirin dosage in this clinical setting.

We thank Dr A. Ryman (Laboratoire d'Hématologie, Hôpital Pellegrin, CHU de Bordeaux, France) for performing the vWF multimers studies, Xavier Pillois for statistical analyses
(Inserm U1034, Adaptation Cardiovasculaire à l'Ischémie, Pessac, France), and Erwan Floch, PharmD (Newmed Publishing Services) for reviewing the manuscript.

\section{References}

1. Slaughter MS, Pagani FD, Rogers JG, Miller LW, Sun B, Russell SD, et al; HeartMate II Clinical Investigators. Clinical management of continuous-flow left ventricular assist devices in advanced heart failure. J Heart Lung Transplant. 2010;29(4 Suppl):S1-39.

2. Flint KM, Matlock DD, Lindenfeld J, Allen LA. Frailty and the selection of patients for destination therapy left ventricular assist device. Circ Heart Fail. 2012;5:286-93.

3. Kirklin JK, Naftel DC, Pagani FD, Kormos RL, Stevenson L, Miller M, et al. Long-term mechanical circulatory support (destination therapy): on track to compete with heart transplantation? J Thorac Cardiovasc Surg. 2012;144: 584-603; discussion 597-8.

4. Westaby S. Cardiac transplant or rotary blood pump: contemporary evidence. J Thorac Cardiovasc Surg. 2013;145:24-31.

5. Rossi M, Serraino GF, Jiritano F, Renzulli A. What is the optimal anticoagulation in patients with a left ventricular assist device? Interact Cardiovasc Thorac Surg. 2012; 15:733-40.

6. John R, Panch S, Hrabe J, Wei P, Solovey A, Joyce L, et al. Activation of endothelial and coagulation systems in left ventricular assist device recipients. Ann Thorac Surg. 2009;88:1171-9.

7. Jennings D, McDonnell J, Schillig J. Assessment of long-term anticoagulation in patients with a continuous-flow left-ventricular assist device: a pilot study. J Thorac Cardiovasc Surg. 2011;142:e1-2.

8. Suarez J, Patel CB, Felker GM, Becker R, Hernandez AF, Rogers JG. Mechanisms of bleeding and approach to patients with axial-flow left ventricular assist devices. Circ Heart Fail. 2011;4:779-84.

9. Houël R, Mazoyer E, Boval B, Kirsch M, Vermès E, Drouet L, et al. Platelet activation and aggregation profile in prolonged external ventricular support. J Thorac Cardiovasc Surg. 2004;128:197-202.

10. Gum PA, Kottke-Marchant K, Welsh PA, White J, Topol EJ. A prospective, blinded determination of the natural history of aspirin resistance among stable patients with cardiovascular disease. J Am Coll Cardiol. 2003;41:961-5. Erratum in: J Am Coll Cardiol. 2006;48:1918.

11. Hunt SA, Frazier OH. Mechanical circulatory support and cardiac transplantation. Circulation. 1998;97:2079-90.

12. Goldstein DJ, Beauford RB. Left ventricular assist devices and bleeding: adding insult to injury. Ann Thorac Surg. 2003;75(6 Suppl):S42-7.

13. Altman R, Luciardi HL, Muntaner J, Herrera RN. The antithrombotic profile of aspirin. Aspirin resistance, or simply failure? Thromb J. 2004;2:1.

14. Blann AD, Kuzniatsova N, Lip GY. Vascular and platelet responses to aspirin in patients with coronary artery disease. Eur J Clin Invest. 2013;43:91-9.

15. Loebe M, Koster A, Sanger S, Potapov EV, Kuppe H, Noon GP, et al. Inflammatory response after implantation of a left ventricular assist device: comparison between the axial flow MicroMed DeBakey VAD and the pulsatile Novacor device. ASAIO J. 2001;47:272-4.

16. Caruso R, Verde A, Campolo J, Milazzo F, Russo C, Boroni C, et al. Severity of oxidative stress and inflammatory activation in end-stage heart failure patients are unaltered after 1 month of left ventricular mechanical assistance. Cytokine. 2012:59:138-44.

17. Jayachandran M, Brunn GJ, Karnicki K, Miller RS, Owen WG, Miller VM. In vivo effects of lipopolysaccharide and TLR4 on platelet production and activity: implications for thrombotic risk. J Appl Physiol (1985). 2007;102:429-33.

18. Pick M, Perry C, Lapidot T, Guimaraes-Sternberg C, Naparstek E, Deutsch V, et al. Stress-induced cholinergic signaling promotes inflammation-associated thrombopoiesis. Blood. 2006;107:3397-406.

19. Arazi HC, Doiny DG, Torcivia RS, Grancelli H, Waldman SV, Nojek C, et al. Impaired anti-platelet effect of aspirin, inflammation and platelet turnover in cardiac surgery. Interact Cardiovasc Thorac Surg. 2010;10:863-7.

20. Brambilla M, Parolari A, Camera M, Colli S, Eligini S, Centenaro C, et al. Effect of two doses of aspirin on thromboxane biosynthesis and platelet function in patients undergoing coronary surgery. Thromb Haemost. 2010;103:516-24.

21. Vane JR, Bakhle YS, Botting RM. Cyclooxygenases 1 and 2. Annu Rev Pharmacol Toxicol. 1998;38:97-120.

22. Weber AA, Zimmermann KC, Meyer-Kirchrath J, Schrör K. Cyclooxygenase-2 in human platelets as a possible factor in aspirin resistance. Lancet. 1999;353: 900 . 
23. Weber AA, Przytulski B, Schumacher M, Zimmermann N, Gams E, Hohlfeld T, et al. Flow cytometry analysis of platelet cyclooxygenase-2 expression: induction of platelet cyclooxygenase-2 in patients undergoing coronary artery bypass grafting. Br J Haematol. 2002;117:424-6.

24. Rocca B, Secchiero P, Ciabattoni G, Ranelletti FO, Catani L, Guidotti L, et al. Cyclooxygenase-2 expression is induced during human megakaryopoiesis and characterizes newly formed platelets. Proc Natl Acad Sci U S A. 2002;99:7634-9.

25. Geisen U, Heilmann C, Beyersdorf F, Benk C, Berchtold-Herz M, Schlensak C, et al. Non-surgical bleeding in patients with ventricular assist devices could be explained by acquired von Willebrand disease. Eur J Cardiothorac Surg. 2008;33:679-84.

26. Uriel N, Pak SW, Jorde UP, Jude B, Susen S, Vincentelli A, et al. Acquired von Willebrand syndrome after continuous-flow mechanical device support contributes to a high prevalence of bleeding during long-term support and at the time of transplantation. J Am Coll Cardiol. 2010;56:1207-13.
27. Klovaite J, Gustafsson F, Mortensen SA, Sander K, Nielsen LB. Severely impaired von Willebrand factor-dependent platelet aggregation in patients with a continuous-flow left ventricular assist device (HeartMate II). J Am Coll Cardiol. 2009;53:2162-7.

28. Heilmann C, Geisen U, Beyersdorf F, Nakamura L, Benk C, Berchtold-Herz M et al. Acquired von Willebrand syndrome in patients with ventricular assist device or total artificial heart. Thromb Haemost. 2010;103:962-7.

29. Bartoli CR, Dassanayaka S, Brittian KR, Luckett A, Sithu S, Siess T, et al Insights into the mechanism(s) of von Willebrand factor degradation during mechanical circulatory support. J Thorac Cardiovasc Surg. 2014; 147:1634-43.

30. Lahpor J, Khaghani A, Hetzer R, Pavie A, Friedrich I, Sander K, et al. European results with a continuous-flow ventricular assist device for advanced heart-failure patients. Eur J Cardiothorac Surg. 2010;37:357-61.

\title{
EDITORIAL COMMENTARY
}

\section{You can't get there from here without more robust data}

\author{
Simon Body, MBChB, MPH, FAHA, ${ }^{a}$ and Gregory Couper, $\mathrm{MD}^{\mathrm{b}}$
}

See related article on pages 3119-25.

Fiore and colleagues ${ }^{1}$ report variability in the effectiveness of aspirin as a platelet-inhibitor measured by lighttransmission aggregometry in patients after HeartMate II (Thoratec Corp, Pleasanton, Calif) ventricular-assist device (VAD) implantation. Like many centers performing VAD surgery, the investigators used a vitamin K pathway inhibitor to achieve an international normalized ratio of 2 to 3 along with oral aspirin to prevent thromboembolism. The clinical issue this study addresses is the value of platelet light-transmission aggregometry (LTA) for assessing the effectiveness of platelet inhibition by aspirin in patients with an axial VAD and reflects a long-standing need. ${ }^{2}$

Resistance to aspirin and anticoagulation management in patients with VAD are unresolved issues open to differing interpretation. ${ }^{3}$ Several factors drive local anticoagulation practices, including device type, pump flow, coagulation measurements used, and past experience. Tailoring anticoagulation to individual patients relies on having a measure or measures of anticoagulant effectiveness that are highly

From the Department of Anesthesiology, Perioperative and Pain Medicine, ${ }^{\mathrm{a}}$ and Division of Cardiac Surgery, ${ }^{\mathrm{b}}$ Brigham and Women's Hospital, Harvard Medical School, Boston, Mass.

Disclosures: Authors have nothing to disclose with regard to commercial support. Received for publication Oct 4, 2014; accepted for publication Oct 6, 2014

Address for reprints: Simon Body, MBChB, MPH, FAHA, Department of Anesthesi-

ology, Perioperative and Pain Medicine, Brigham and Women's Hospital, 75

Francis St, Boston, MA 02115 (E-mail: body@zeus.bwh.harvard.edu).

J Thorac Cardiovasc Surg 2014;148:3125-6

$0022-5223 / \$ 36.00$

Copyright (c) 2014 by The American Association for Thoracic Surgery

http://dx.doi.org/10.1016/j.jtcvs.2014.10.026 associated with important patient outcomes. The clinical problem is complicated by uncertainty regarding which therapeutic targets to use to measure the multifaceted components of the coagulation cascade in patients with VAD. ${ }^{4}$ It is further complicated by temporal variation in coagulation status, from immediate postoperative coagulopathy to the procoagulant environment that is a nearly universal response to VAD placement, in part from VAD-induced loss of highmolecular-weight von Willebrand factor multimers. ${ }^{5}$ Individual variability in aspirin responsiveness, anticoagulant drug metabolism, circulating levels of coagulation factors, platelet count and fibrinolytic activity, and etiologic cardiac disease is seen in patients with a VAD and in cardiac populations and determines coagulation status and response to anticoagulants and antiplatelet agents. ${ }^{6,7}$ This variation predicts a failure of 1-size-fits-all anticoagulation strategies and drives the need for research such as this study to nail down this issue. Further, there is no proven advantage to steering either an anticoagulant or a procoagulant course-both are bad. Embolic stroke is an event feared by patients more than death and the physician response to bleeding is often to reduce the level of anticoagulation, resulting in a greater incidence of embolic events. ${ }^{8}$

This study has potential value for its reliance upon LTA to determine an appropriate long-term aspirin dosing in their patients over a period of more than 8 months but is limited by the small cohort size. The study observations of wide variability in aspirin dose required to achieve platelet inhibition measured by LTA, and that the majority of patients required aspirin doses several times higher than those required to achieve platelet inhibition in ambulatory coronary artery disease $^{2}$ are valuable. Although the authors state that adjustment of aspirin dosing according to LTA reduced the rate of 


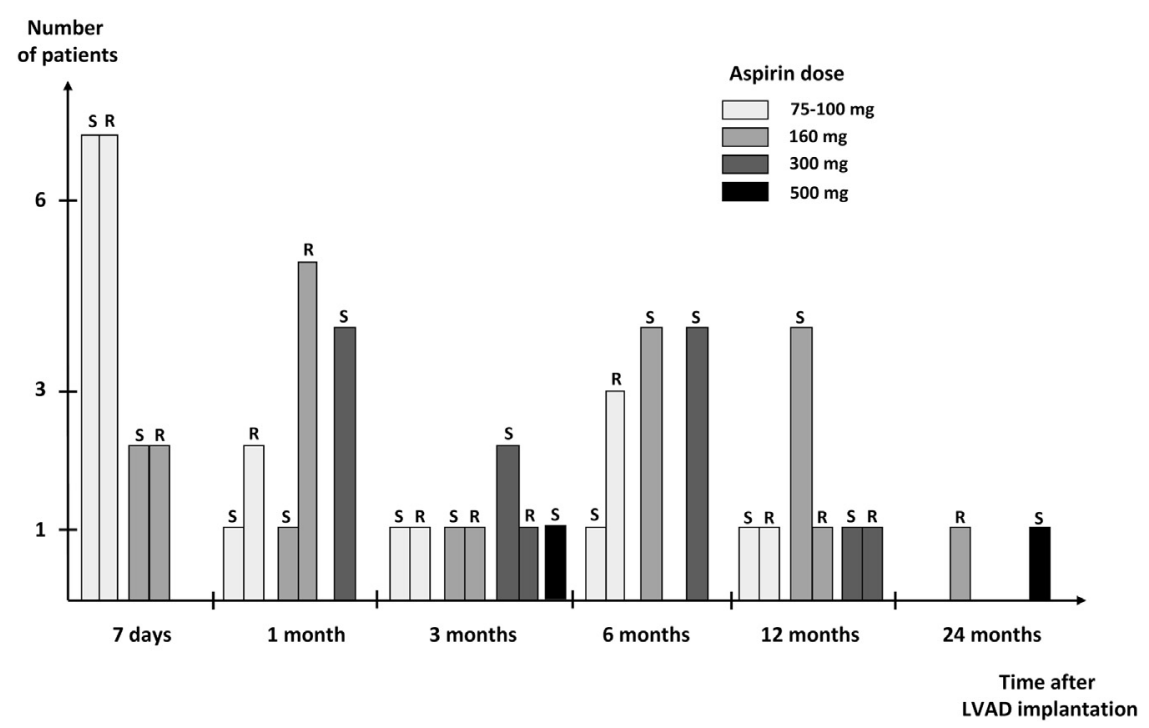

FIGURE E1. Platelet aggregation testing in the presence of arachidonic acid $(0.5 \mathrm{mg} / \mathrm{mL})$. Resistance to aspirin treatment $(R)$ was defined as persisting platelet aggregation greater than $20 \%$ despite daily administration of aspirin. S, Aspirin sensitivity; $L V A D$, left ventricular assist device. 